\title{
NUMERICAL AND EXPERIMENTAL STUDY ON SEAKEEPING PERFORMANCE OF A HIGH-SPEED TRIMARAN WITH T-FOIL IN HEAD WAVES
}

\author{
Ang Li ${ }^{\text {a }}$ \\ Yunbo Li $^{\text {b }}$ \\ ${ }^{a}$ Harbin Engineering University, China \\ b Shanghai Maritime University, China
}

\begin{abstract}
The longitudinal motion characteristics of a slender trimaran equipped with and without a T-foil near the bow are investigated by experimental and numerical methods. Computational fluid dynamics (CFD) method is used in this study. The seakeeping characteristics such as heave, pitch and vertical acceleration in head regular waves are analyzed in various wave conditions. Numerical simulations have been validated by comparisons with experimental tests. The influence of large wave amplitudes and size of T-foil on the longitudinal motion of trimaran are analyzed. The present systematic study demonstrates that the numerical results are in a reasonable agreement with the experimental data. The research implied that the longitudinal motion response values are greatly reduced with the use of T-foil.
\end{abstract}

Keywords: trimaran; T-foil; URANS; longitudinal motion; model test

\section{INTRODUCTION}

Improving a ship's seakeeping performance and enhancing its navigational performance under stormy wave conditions has always been crucial research topics in the marine industry. More and more research works on high-performance vehicles and stabilization techniques have been made in recent years. Trimarans are currently of interest for many new highspeed ship projects due to their high level of hydrodynamic efficiency.

Compared with monohull and catamaran, the trimaran has excellent navigation and high-speed performance $[1,2]$. Large amount of efforts have been focused on developing experimental and numerical methods to predict the seakeeping performance of trimarans. In the work [3] two different designs for target trimaran were studied. The first one had a round bilge hull and asymmetric side hulls and the other one had a Deep-V hull and symmetric side hulls. Comparison of the resistance and seakeeping qualities of the two different trimaran designs tested in model scale were presented in their paper. In [4] model tests were conducted on multiple trimarans, and the influence of trim, hull form and outrigger layout on the resistance and seakeeping performance were analyzed. In [5] the effects of the stagger of the side hulls on the motions in heave and pitch of a trimaran hull were investigated. Despite the model experiments were still valuable the use of CFD method was getting in common. CFD approaches widely used by researchers can be classified into two main categories, namely, based on potential theory and RANS method. For the prediction of seakeeping performance some methods could be found in the literature : in [6] the high-speed slender body potential flow theory (also called two and a half dimensional potential flow theory, 2D+t or 2.5D), was first developed. The method effectively solved the shortcomings of the STF method in the prediction of multihull ship seakeeping [7]. In [8] the vertical motions of a trimaran with different Froude numbers were calculated by using $2.5 \mathrm{D}$ theory. The authors demonstrated that the results of the $2.5 \mathrm{D}$ method for prediction of the trimaran waveinduced motions are in agreement with the experimental results. In [9] a series of model tests in regular head waves were conducted for one trimaran with different outrigger layouts at the Froude numbers of 0.471 and 0.628 . The authors pointed out that the numerical model of $2.5 \mathrm{D}$ is based on the linear potential flow theory and hence cannot capture the 
influence of the violent green water on the heave motions, and that this could cause an error in the numerical results.

In the traditional potential theory viscosity and nonlinearity effects are not taken into account, thus it may cause errors. As computational facilities have become more powerful and accessible, CFD tools are now increasingly used to predict ship motions. In [10] a numerical method for the prediction of motion performance of a trimaran with a long bulb and a transom stern was developed and its accuracy was assessed by the comparison with experiments. The unsteady Reynolds-averaged Navier-Stokes equations are solved with the density function technique for the free surface treatment. The research showed that the heave and pitch motions were predicted with reasonable accuracy. In [11] ship motions and added resistance of a high-speed trimaran in regular head waves were predicted by using CFD tools. In [12] CFD tools were used to investigate the optimization of a trimaran yacht equipped with axebow. The study was focused on the analysis of resistance and seakeeping qualities which could provide the best performance to the yacht.

When the trimaran navigates under high speed, the longitudinal motion responses may be large. The vertical acceleration will cause severe seasickness of passengers and crew [13]. In order to reduce longitudinal motion responses of fast ferries, different kinds of motion control devices have been developed to increase comfort of passengers. In recent years, T-foils has been widely installed on fast ferries due to its small size and obvious effects. It is fixed under the bow, providing the restoring force and moment, and it can reduce the pitch and heave motion of the fast ferries [14]. The INCAT corporation engaged in the study of anti-vertical motion appendages, developed fixed and retractable T-foil and cooperated with Maritime Dynamics Inc. (MDI) to design the Ride Control System (RCS) which can adjust the restoring force and moment generated by T-foil when the ship moves in waves [15]. In [14-16] many numerical simulations and model tests of the high speed monohull craft with T-foil and flaps were conducted. The authors pointed out that the vertical acceleration and MSI (Motion Sickness Index) of the fast ferry were reduced by 65 and 35\%, respectively, with the actuators moving under control. In [17] an experimental study (model tests) was conducted on a trimaran with controlled T-foil, three different ship models including a bare hull, a hull with non-controlled T-foil and a hull with an active controlled T-foil. In the study, the efficacy of the non-controlled and controlled T-foil were reported and discussed. There are limited studies based on URANS method on the reduction of vertical motion of the trimaran by means of T-foil. The present study primarily deals with the seakeeping performance of a trimaran with T-foil near the bow in regular head waves, investigated by using experimental and numerical methods.

In the present study, the numerical simulations and experimental tests for the prediction of the ship motions of trimaran with and without T-foil in regular head waves are carried out. The numerical method is based on URANS method. Both free heave and pitch motions in head waves are simulated. The obtained numerical results are validated with the use of experimental data. During the study, the grid convergence tests are also carried out for the URANS approach. The longitudinal motion of the ship is examined in various wave conditions. Unsteady wave patterns and the time history results of the longitudinal ship motion responses in waves are simulated by using the CFD tool. To investigate the influence of T-foil on hydrodynamic performance of high-speed trimaran in regular head waves, two cases are considered: bare trimaran and trimaran with T-foil. The influence of large wave amplitudes and size of T-foil on the longitudinal motion of trimaran are analyzed.

\section{DESCRIPTION OF THE TRIMARAN AND T-FOIL}

A numerical simulation and small-scale model test of the trimaran were carried out. The body plan of the main hull and outriggers are shown in Fig. 1. The main characteristics of the model are given in Tab. 1 .

The dimensions of the T-foil installed on the trimaran model near the bow are indicated in Tab. 2. The T-foil is composed of a vertical foil and an airfoil with the attack angle of $\pm 5^{\circ}$. It is assumed that the counter-clockwise rotation angle of the T-foil is positive. The geometrical image of the trimaran equipped with the T-foil and stern flap is shown in Fig. 2.
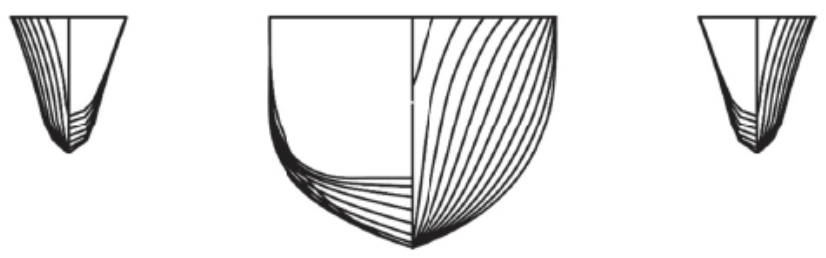

Fig. 1 Lines drawing of the trimaran

Tab. 1 Main characteristics of the trimaran model

\begin{tabular}{|c|c|c|}
\hline \multirow[t]{2}{*}{ Main feature } & \multicolumn{2}{|c|}{ Value } \\
\hline & Middle Hull & Side Hull \\
\hline Length overall (m) & \multicolumn{2}{|c|}{3.343} \\
\hline Breadth $(\mathrm{m})$ & \multicolumn{2}{|c|}{0.641} \\
\hline Depth (m) & \multicolumn{2}{|c|}{0.249} \\
\hline Length at waterline (m) & 3.0 & 1.071 \\
\hline Beam at waterline $(\mathrm{m})$ & 0.24 & 0.051 \\
\hline Draft (m) & 0.122 & 0.043 \\
\hline Displacement (kg) & \multicolumn{2}{|c|}{45.99} \\
\hline Longitudinal radius of gyration (m) & \multicolumn{2}{|c|}{0.807} \\
\hline $\begin{array}{l}\text { Ratio of main hull displacement and } \\
\text { outriggers displacement }\end{array}$ & \multicolumn{2}{|c|}{14.333} \\
\hline
\end{tabular}


Tab. 2 Dimensions of the T-foil

\begin{tabular}{|l|l|}
\hline Principal particulars & Value \\
\hline Airfoil shape & NACA0012 \\
\hline Span $(\mathrm{m})$ & 0.144 \\
\hline Chord $(\mathrm{m})$ & 0.096 \\
\hline Aspect ratio & 1.5 \\
\hline Rotating angle of the flap () & \\
\hline Width of the vertical foil $(\mathrm{m})$ & 0.01 \\
\hline Length of the vertical foil (m) & 0.060 \\
\hline Height of the vertical foil (m) & 0.024 \\
\hline $\begin{array}{l}\text { Longitudinal position of installed foil (distance between } \\
\text { vertical centre line of foil and } 10^{\text {th }} \text { theoretical station of } \\
\text { the trimaran body) (m) }\end{array}$ & 1.320 \\
\hline
\end{tabular}

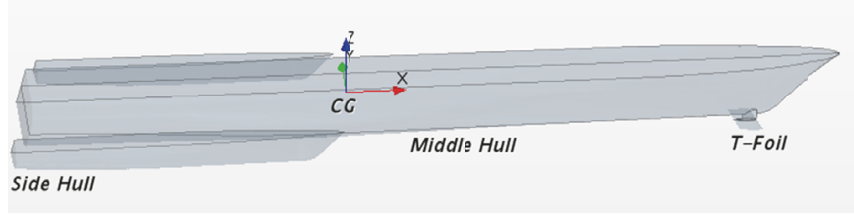

Fig. 2 Geometrical image of the trimaran with T-foil

\section{EXPERIMENTAL SETUP}

Model tests were conducted at the Harbin Engineering University towing tank whose dimensions are: $108 \mathrm{~m}, 7 \mathrm{~m}$ and $3.5 \mathrm{~m}$ in length, width and depth, respectively. There is a wave maker at one end of the towing tank, and a wave dissipation bank at the other end of the towing tank. The maximum speed of the towing carriage over the tank is $6.5 \mathrm{~m} / \mathrm{s}$. The waves generated by the wave generator are measured with the use of a wave probe. The four - motion measurement device (heave, pitch, roll and surge) is used to measure the ship model motions.

The bare trimaran hull model and the model fitted with a T-foil and stern flap are used for the model tests. The model free to trim and sink was run first in calm water to obtain the basic resistance. The models were then run in a seaway to allow the ship wave-generated motions to be observed. The heave, pitch and vertical acceleration at 19 th hull station near the bow in different wave conditions were measured. Fig. 3 shows the experimental setup for the model test.

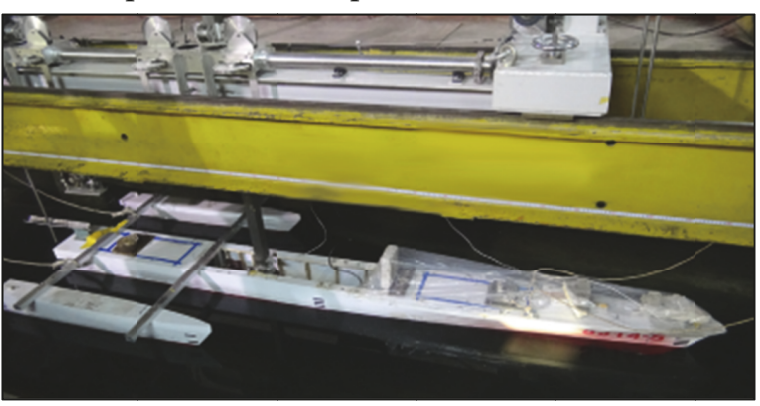

Fig. 3 Experimental setup for seakeeping tests
The forward speed $U$ was set at $3.408 \mathrm{~m} / \mathrm{s}$, and the corresponding Froude number $\mathrm{F}_{\mathrm{n}}$ was equal to 0.628 . For the entire seakeeping tests, the wave amplitude $\zeta$ changed with wave length. The wavelength $\lambda$ varied between $1.5 \mathrm{~m}$ and $6.75 \mathrm{~m}$, thus the ratio $\lambda / \mathrm{L}$ varied between 0.50 and 2.25 . The numerical simulations were conducted in the same test conditions as for the model tests. The CFD simulations and model tests were performed for eleven different conditions listed in Tab. 3, (identified by their case numbers). The wave encounter frequency $\mathrm{f}_{e}[\mathrm{~Hz}]$ is calculated from the formula $f_{e}=\sqrt{g / 2 \pi \lambda}+U / \lambda$ for head seas (where $g$ - the gravitational acceleration, and $U$ - the ship forward speed [ $\mathrm{m} / \mathrm{s}]$ ).

Tab. 3 Simulation and model test conditions

\begin{tabular}{|c|c|c|c|c|c|}
\hline 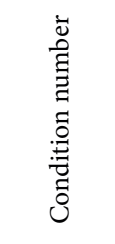 & 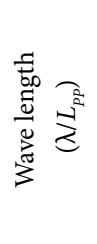 & 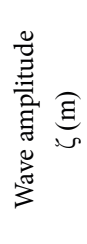 & 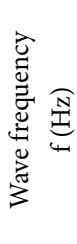 & 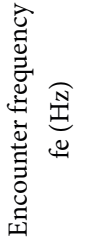 & 获 \\
\hline $\begin{array}{c}\text { C0 (calm } \\
\text { water) }\end{array}$ & - & - & - & - & - \\
\hline $\mathrm{C} 1$ & 0.50 & 0.015 & 1.020 & 3.292 & 0.063 \\
\hline C2 & 0.75 & 0.0225 & 0.833 & 2.348 & 0.063 \\
\hline C3 & 0.88 & 0.025 & 0.769 & 2.060 & 0.059 \\
\hline $\mathrm{C} 4$ & 1.0 & 0.03 & 0.721 & 1.857 & 0.063 \\
\hline C5 & 1.25 & 0.03 & 0.645 & 1.554 & 0.050 \\
\hline C6 & 1.38 & 0.03 & 0.614 & 1.437 & 0.046 \\
\hline C7 & 1.60 & 0.04 & 0.570 & 1.280 & 0.052 \\
\hline C8 & 1.75 & 0.04 & 0.545 & 1.194 & 0.048 \\
\hline C9 & 2.0 & 0.05 & 0.510 & 1.078 & 0.052 \\
\hline C10 & 2.25 & 0.05 & 0.481 & 0.986 & 0.047 \\
\hline
\end{tabular}

\section{NUMERICAL SIMULATION METHOD}

This section provides details of the numerical simulation approaches used in this study and discussion of the numerical methods applied to the current CFD model.

\section{GOVERNING EQUATIONS}

An URANS approach was applied to calculate the added resistance and ship motions in regular waves by using the STAR-CCM+ commercial CFD software [18]. The governing equations are the RANS equations and continuity equation for mean velocity of the unsteady, three-dimensional 
incompressible flow. The averaged continuity and momentum equations are given by Eq. (1) and Eq. (2) in tensor form in the Cartesian coordinate system.

$$
\begin{gathered}
\frac{\partial\left(\rho \bar{u}_{i}\right)}{\partial x_{i}}=0 \\
\frac{\partial \rho \bar{u}_{i}}{\partial t}+\frac{\partial}{\partial x_{j}}\left(\rho \bar{u}_{i} \bar{u}_{j}+\rho \overline{u_{i}^{\prime} u_{j}^{\prime}}\right)=-\frac{\partial \bar{p}}{\partial x_{i}}+\frac{\partial \bar{\tau}_{i j}}{\partial x_{j}}
\end{gathered}
$$

where $\bar{u}$ is the relative averaged velocity vector of flow between the fluid and the control volume, $\overline{u_{i}^{\prime} u_{j}^{\prime}}$ is the Reynolds stresses and $\bar{p}$ is the mean pressure. For Newtonian fluid under three-dimensional incompressible flow, the mean shear stress tensor $\bar{\tau}_{i j}$ can be expressed as follows :

$$
\bar{\tau}_{i j}=\mu\left(\frac{\partial \bar{u}_{i}}{\partial x_{j}}+\frac{\partial \bar{u}_{j}}{\partial x_{i}}\right)
$$

where $\mu$ is dynamic viscosity.

The equation for the translation of the centre of mass of the ship body is given as:

$$
m \frac{d v}{d t}=f
$$

where $\mathrm{m}$ represents the mass of the body, $\mathrm{f}$ is the resultant force acting on the body and $\mathrm{v}$ is the velocity of the centre of mass. An angular momentum equation of the body is formulated in the body local coordinate system with the origin in the centre of the body:

$$
M \frac{d \omega}{d t}+\omega \times M \omega=n
$$

where $\mathrm{M}$ is the tensor of moments of inertia, is the angular velocity of rigid body, and $\mathrm{n}$ is the resultant moment acting on the body. The resulting force and moment acting on the ship are obtained from fluid pressure and shear force acting on each boundary face of the body. The translations of the ship are estimated according to the computed velocity and pressure fields in the flow domain.

\section{PHYSICAL PHENOMENA MODELLING}

The "Finite Volume Method" (FVM) was applied to the spatial discretization. The "Volume of Fluid " (VOF) method was used to model the free surface, either with a flat wave in the simulation of calm-water resistance or first-order regular wave in the calculation of ship motion in waves. The VOF model is based on the assumption that the same basic governing equations as those used for a single-phase problem can be solved for all the fluid phases present within the domain, as it is assumed that they will have the same velocity, pressure and temperature. This means that the equations are solved for an equivalent fluid whose properties represent the different phases and their respective volume fractions. The grid is simply refined to enable the variations in volume fraction to be more accurately captured. In this work, a second-order convection scheme was used throughout all the simulations to accurately capture interface between the phases. The flow equations were solved in a segregated manner by using a predictor-corrector approach. Convection and diffusion terms in the RANS equations were discretized by a second-order upwind scheme and a central difference scheme. The semi-implicit method for pressure-lined equations (SIMPLE) algorithm [19] was used to resolve the pressurevelocity coupling. The turbulent model selected in this study was a SST k-w turbulence model which has the ability to simulate the complex flow problems with flow separation and strong adverse pressure gradients. In order to simulate the seakeeping behaviour of the trimaran, the Dynamic Fluid Body Interaction (DFBI) model was used to allow the model to move free in heave and pitch modes. The DFBI model enabled the RANS solver to calculate the exciting force and moments acting on the hull due to wave forces, and to solve the governing equations of rigid body motion to reposition the grid body [20]. The overset mesh allowed all motions to be simulated without the risk of badly deforming cells, thus enabling the simulation of large amplitude motions.

\section{COMPUTATIONAL DOMAIN, BOUNDARY CONDITIONS AND MESHES}

A general view of the computational domain with the trimaran is shown in Fig. 4. The boundary conditions are

\begin{tabular}{|c|c|c|c|c|c|c|c|}
\hline 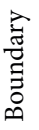 & $\frac{\overrightarrow{ \pm}}{\Xi}$ & 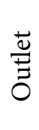 & $\frac{\pi}{\pi}$ & 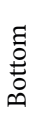 & 。ำ & 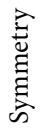 & 点 \\
\hline 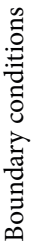 & 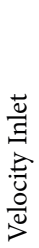 & 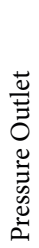 & 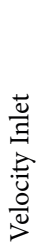 & 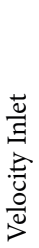 & 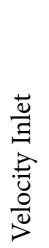 & 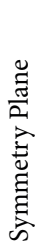 & 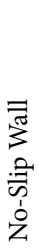 \\
\hline
\end{tabular}
given in Tab. 4.

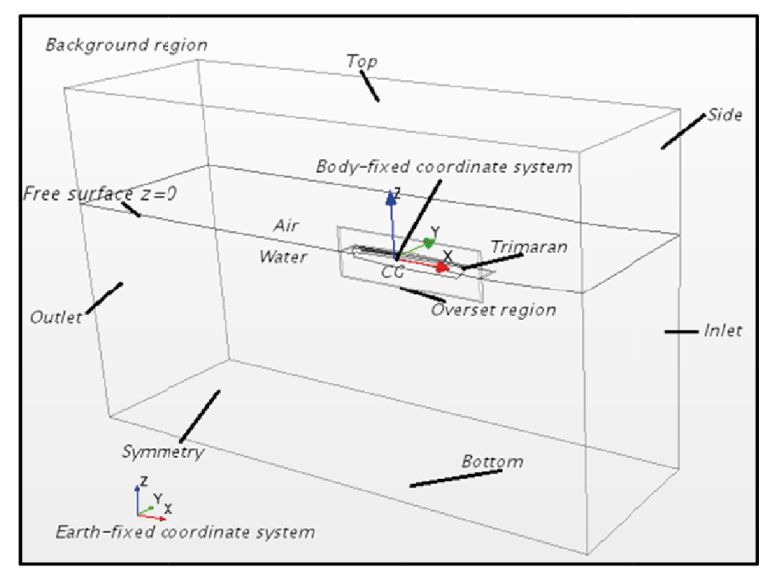

Fig.4 General view of computational domain and boundaries

Tab. 4 Boundary conditions 
Two different coordinate systems were applied to predict ship performance. One is the earth-fixed coordinate system and another one is the moving coordinate system located at the centre of gravity (CG) of the trimaran. The origin of the inertial frames was located on the base line of the ship at its aft perpendicular. The origin of the ship-fixed reference frames was situated at their centre of gravity (CG). First , the flow field was solved, and the exciting force and moments acting on the hull were calculated in the earth-fixed coordinate system. Then, the forces and moments were converted to the moving coordinate system. The motions of the trimaran were described by translations and rotations with respect to the centre of gravity in the earth-fixed coordinate system. The equations of motions were solved to calculate the ship velocities and then they were converted back to the earthfixed coordinate system. These information sets were then used to find the new location of the ship and grid system. The overset grid system was re-positioned after each time step. The authors of [21] recommend that for simulations in the presence of incident waves, the inlet boundary should be located $(1 \div 2) L_{B P}$ away from the hull, whereas the outlet should be positioned $(3 \div 5) L_{B P}$ downstream to avoid any wave reflection from the boundary walls. The trimaran symmetry about its centre plane of the middle hull allowed to discretize only one-half of the computational domain. Therefore only a half of the trimaran and control volume were considered in all the calculations; thus, the symmetry plane formed the centreline domain face to reduce computational time. The mid-plane of the ship is located at $\mathrm{y}=0$ and ship draught $(\mathrm{T})$ is $\mathrm{z}=0$. The dimensions of the boundaries are shown in Fig. 5. which gives front and side views of the computation domain.

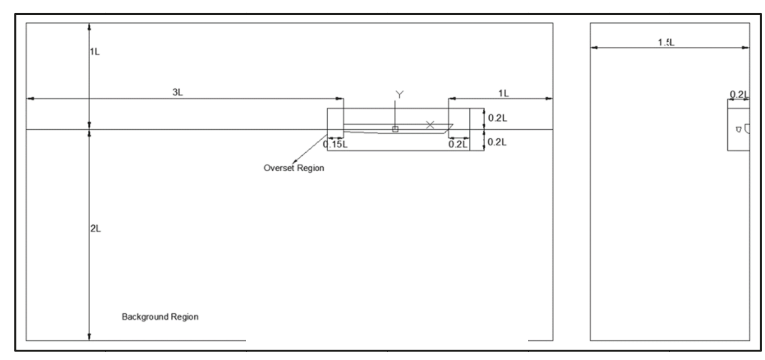

(a) Front view

(b) Side view

Fig. 5. The dimensions of the computational domain

The inlet boundary was located one model length ahead of the model's forward perpendicular; the outlet boundary - three model lengths behind the model's aft perpendicular; the bottom - two model lengths below the calm water surface; the top - one model length above the calm water surface and one model length between symmetry boundary and side boundary. The velocity-inlet boundary condition was set in the positive $\mathrm{x}$ - direction, where first - order incident regular waves were generated. The velocities of the incident wave were directly set to the inlet boundary to generate the required regular wave. The negative $\mathrm{x}$ - direction was modelled as a pressure-out. The top, bottom and side boundaries were selected as velocity-inlet. The symmetry plane forms a symmetry condition. The trimaran hull was regarded as a rigid body and set as no-slope wall. In order to prevent the undesirable effect of the reflected waves from the outlet boundary, artificial wave damping capability of the software package [22] was applied to the outlet boundary in background region with a damping length equal to1.5 ship length.

There are three methods, namely : that of rigid motion, deforming mesh motion and overset mesh, which can be chosen. The rigid motion and deforming mesh motion methods have distinct disadvantages compared to the overset mesh method when simulating bodies with large amplitude motions. The rigid motion approach causes difficulties for free surface refinement, especially in pitch, and deforming meshes may lead to cell quality problems. The authors of [23] showed that the overset grid method was more accurate in the prediction of the motion response of an SSB catamaran under regular wave conditions when heading in the wave. The overset region moves with the hull over a static background region. In fact, using the overset mesh saves computational costs and allows to generate a sufficiently refined mesh configuration around the free surface and the body. Since the overset mesh was used, two different regions, named background region and overset region, were established to simulate ship responses in calm water and waves. An interface was produced between the background region and overset region to transfer fluid information. Mesh generation was performed by using the automatic meshing facility in STAR$\mathrm{CCM}+$ software. A trimmed cell mesher was employed to produce a high-quality grid for complex mesh generating problems. The ensuing mesh was formed primarily of unstructured hexahedral cells with trimmed cells adjacent to the surface. Prism layers were applied around the trimaran to resolve the turbulent boundary layer at the no-slip surface and mesh control volumes were produced to refine the meshes near the free surface and the hull surface together with the surfaces of anti-pitching appendages. Fig. 6 presents a general view of the computational mesh showing the background and overset domains. As shown in Fig. 6, near the free surface and around the hull, local mesh refinements were applied to resolve the wave pattern and the incident wave field. Fig. 7 provides a closer look at the mesh around the ship hull and anti-pitching appendages.

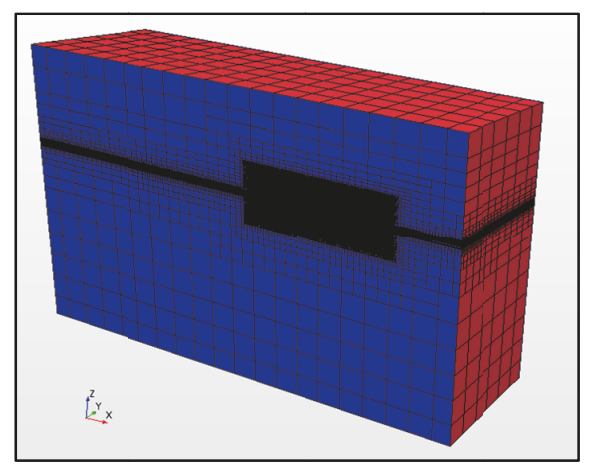

Fig.6 A general view of the meshes for the whole domain 


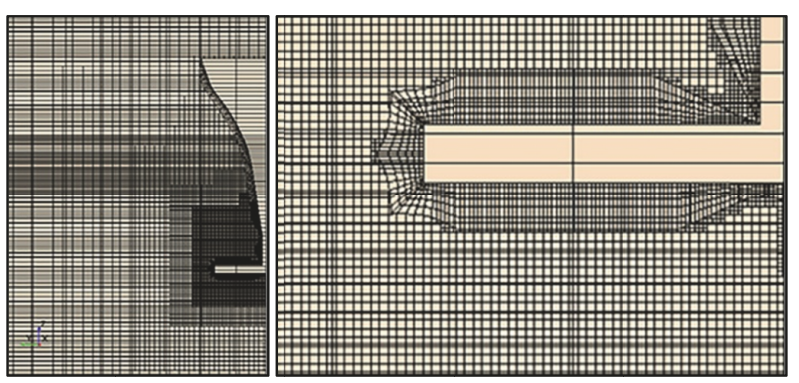

Fig.7 (a) Meshes around the bow (b) Meshes around the T-foil

\section{VERIFICATION AND VALIDATION FOR CFD SIMULATION}

In this section, following the method presented in [24], verification and validation $(\mathrm{V} \& \mathrm{~V})$ was performed to quantify errors and uncertainties in CFD simulations.

It is necessary to mention that the transfer functions of heave, pitch and acceleration motions were calculated as follows:

$$
\begin{gathered}
T F_{3}=\frac{Z_{a}}{\zeta_{a}} \\
T F_{5}=\frac{\phi}{k \zeta_{a}} \\
A_{19}=\frac{A L_{B P}}{g \zeta_{a}}
\end{gathered}
$$

Where $Z, \Phi, A$ and $\zeta$ represent the first Fourier Series (FS) harmonic amplitudes of heave, pitch, acceleration and incident wave amplitude time histories, respectively. Corresponding Fourier transform equations may be referred to [25]. In this paper, the longitudinal motions of heave and pitch were evaluated at the ship's centre of gravity (CG) and the vertical acceleration was evaluated at the 19 th hull station near the bow.

\section{VERTIFICATION}

A verification study was carried out to assess the numerical uncertainty $U_{S N^{\circ}}$ Grid convergence test was performed at the wave-ship length ratio $\lambda / L=1.38$, which corresponds to the near-resonant physical conditions for heave motion [9], since large motions and accelerations tend to cause the highest numerical errors. The verification parameters included the wave amplitude $\zeta_{a}$, the heave and pitch transfer functions $\mathrm{TF}_{3}, \mathrm{TF}_{5}$ and vertical acceleration at $19^{\text {th }}$ hull station $\left(A_{19}\right)$ near the bow, respectively.

The convergence studies were performed for three cases by using systematically refined grids and time steps. Often in implicit unsteady simulations, the time step is determined by the flow properties. In [26] there is recommended the use of at least 100 time steps per period for motion responses. In this paper, a small time step (1/256 of the encounter period) was used as a base time step. The coarse and fine mesh systems are derived by reducing and increasing cell numbers per wavelength and cell height on free surface, respectively, by using a factor of $\sqrt{ } 2$ [27] as well as cell numbers on and around

\begin{tabular}{|c|c|c|c|c|c|c|c|c|c|c|}
\hline Parameter & $r_{G}$ & $\begin{array}{l}\text { Fine } \\
S_{1}\end{array}$ & $\begin{array}{r}\text { Base } \\
\qquad S_{2}\end{array}$ & $\begin{array}{c}\text { Coarse } \\
\qquad S_{3}\end{array}$ & $R_{G}$ & $\delta_{G}^{*}\left(\% S_{1}\right)$ & $U_{G}\left(\% S_{1}\right)$ & $U_{G_{C}}\left(\% S_{1}\right)$ & $S_{C}$ & EFD (D) \\
\hline$\zeta$ & $\sqrt{2}$ & 28.017 & 27.831 & 27.592 & 0.777 & -0.663 & 5.595 & 1.644 & 28.202 & 28.255 \\
\hline $\mathrm{T} F_{3}$ & $\sqrt{2}$ & 1.490 & 1.502 & 1.518 & 0.774 & 0.805 & 6.658 & 1.951 & 1.478 & 1.425 \\
\hline $\mathrm{T} F_{5}$ & $\sqrt{2}$ & 0.982 & 0.969 & 0.952 & 0.747 & -1.332 & 9.108 & 2.592 & 0.995 & 1.039 \\
\hline$A_{19}$ & $\sqrt{2}$ & 87.697 & 86.917 & 85.918 & 0.782 & -0.890 & 7.783 & 2.297 & 88.478 & 88.869 \\
\hline
\end{tabular}
the ship hull, which is affected by the mesh refinement on free

Tab. 6 Results of grid convergence study.

\begin{tabular}{|c|c|c|c|c|c|c|c|c|c|c|}
\hline Parameter & $r_{T}$ & $\begin{array}{r}\text { Fine } \\
S_{1}\end{array}$ & $\begin{array}{r}\text { Base } \\
S_{2}\end{array}$ & $\begin{array}{c}\text { Coarse } \\
S_{3}\end{array}$ & $R_{T}$ & $\delta_{T}^{*}\left(\% S_{1}\right)$ & $U_{T}\left(\% S_{1}\right)$ & $U_{T_{C}}\left(\% S_{1}\right)$ & $S_{T}$ & EFD (D) \\
\hline$\zeta$ & $\sqrt{2}$ & 28.017 & 27.811 & 27.545 & 0.770 & -0.732 & 5.910 & 1.726 & 28.222 & 28.255 \\
\hline $\mathrm{T} F_{3}$ & $\sqrt{2}$ & 1.490 & 1.505 & 1.523 & 0.777 & 0.968 & 8.159 & 2.397 & 1.476 & 1.425 \\
\hline $\mathrm{T} F_{5}$ & $\sqrt{2}$ & 0.982 & 0.968 & 0.950 & 0.757 & -1.424 & 10.496 & 3.024 & 0.996 & 1.039 \\
\hline$A_{19}$ & $\sqrt{2}$ & 87.697 & 86.697 & 85.408 & 0.776 & -1.140 & 9.546 & 2.802 & 88.697 & 88.869 \\
\hline
\end{tabular}

Tab. 7 Results of time step convergence study. 
surface. The simulation time step is set to be proportional to the grid size $[28,29,30]$.

The grid convergence study was carried out with the small time step $\Delta \mathrm{t}=T_{e} / 362$ in three calculations in which the grid size was systematically coarsened by a uniform refinement ratio of $r_{G}=\sqrt{2}$ in each direction, while the time step convergence study was carried out with a time step refinement ratio of $r_{T}=\sqrt{2}$ on the fine grid. The base and coarse mesh were generated by changing the base size of grid only in the overset region, which means that the background mesh configuration was not altered [20]. This enabled the incident head waves to be modelled efficiently through the computational domain. Otherwise, the incident head waves would not have been captured well with a coarser grid, thus leading to wrong results. Although the mesh changed, the size of prism layers around the hull surface remained the same. The value of yplus on the hull surface were between $30 \div 100$ as shown in Fig. 8 and Fig. 9. The mesh cell numbers for each mesh configuration are listed in Tab. 5.

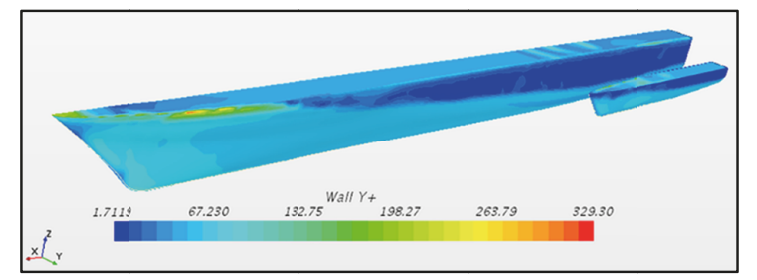

Fig.8 Yplus distribution on the hull surface

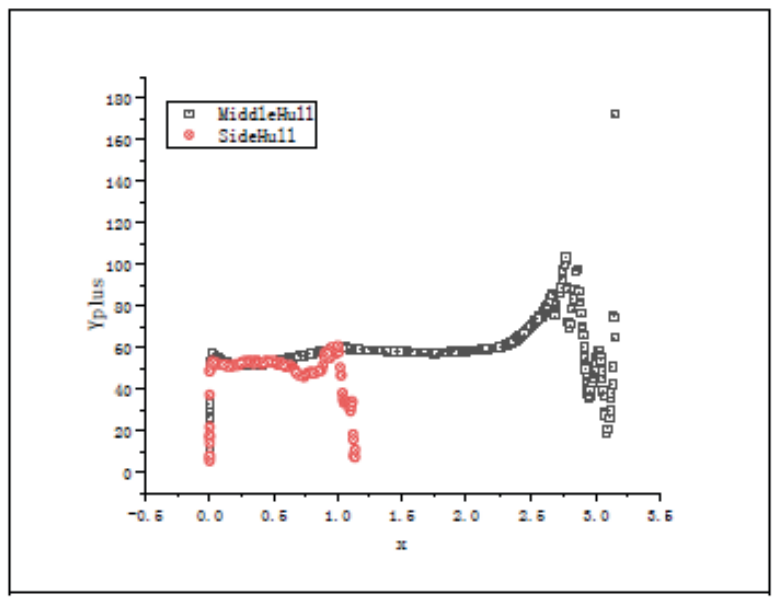

Fig.9 Yplus distribution on the hull surface

Tab. 5 The final cell numbers for each mesh configuration in the grid convergence study.

\begin{tabular}{|c|l|c|c|c|}
\hline Grid name & $\begin{array}{l}\text { Mesh con- } \\
\text { figuration }\end{array}$ & \multicolumn{3}{|c|}{ Grid number (Million) } \\
\hline & & Background & Overset & Total \\
\hline$G_{1}$ & Fine & 1.092 & 5.040 & 6.132 \\
\hline$G_{2}$ & Base & 1.092 & 2.229 & 3.321 \\
\hline$G_{3}$ & Coarse & 1.092 & 1.055 & 2.147 \\
\hline
\end{tabular}

The results of grid and time step convergence studies are listed in Tab. 6 and 7. Let's consider the situation of three solutions corresponding to fine $S_{K 1}$, base $S_{K 2}$, and coarse $S_{K 3}$ values for the $\mathrm{k}^{\text {th }}$ input parameter. To assess the convergence condition, $R_{k}$ acc. Eq. (9) is used as the convergence ratio:

$$
R_{k}=\frac{\varepsilon_{k 21}}{\varepsilon_{k 32}}
$$

where $\varepsilon_{k 21}=S_{k 2}-S_{k 1}$ is the difference between the results of base mesh and fine mesh, and $\varepsilon_{k 32}=S_{k 3}-S_{k 2}$ is the difference between the results of coarse mesh and base mesh. Subscript k refers to the $\mathrm{k}^{\text {th }}$ input parameter. $S_{C}$ is the corrected simulation value calculated as $S_{c}=\mathrm{S}-\delta^{*}$ where $S$ is the simulation results, $\delta^{*}$ is the corrected value. $U_{C}$ is the corrected uncertainty.

Tab. 8 Results of grid convergence study.

\begin{tabular}{|l|c|c|c|c|}
\hline Parameter & $(\% \mathrm{D})$ & & $(\% \mathrm{D})$ & $\mathrm{E}(\% \mathrm{D})$ \\
\hline & 8.069 & 2.5 & 8.447 & 0.844 \\
\hline & 11.014 & 2.5 & 11.294 & -4.589 \\
\hline & 13.137 & 2.5 & 13.373 & 5.463 \\
\hline & 12.154 & 2.5 & 12.409 & 1.319 \\
\hline
\end{tabular}

As shown in Tab. 6 and 7, monotonic convergence was achieved for $\zeta_{a}, T F_{3}, \mathrm{~T} F_{5}$, and $A_{19}$. The uncertainty estimated for the wave amplitude, motion transfer functions and vertical acceleration at $19^{\text {th }}$ hull station were reasonable small. The grid uncertainty $U_{G}(9.108 \%)$ and the time step uncertainty $U_{T}(10.496 \%)$ are relatively large for the pitch transfer function $\mathrm{T} F_{5}$ these values are reduced to $2.592 \%$ and $3.024 \%$ , respectively, when the corrected uncertainties $U_{G_{C}}$ and $U_{T_{C}}$ are estimated. The time step uncertainties $U_{T}$ are generally larger than those of the grid uncertainties $U_{G}$, which indicates that the numerical results are relatively more sensitive to the time step resolution.

\section{VALIDATION}

To determine modelling errors, the numerical results were compared to the experimental data. The experimental data uncertainty was assumed to be of a rather low value $U_{D}=2.5 \%$. The validation uncertainty $U_{v}$ and the comparison error $\mathrm{E}$ were calculated and summarized in Tab. 8. As indicated in Tab. 9, the wave amplitude, the heave, pitch transfer function as well as the vertical acceleration can be considered validated since the comparison error $\mathrm{E}$ is smaller than the validation uncertainty $U_{v}$. The uncertainty levels are estimated to be $8.447 \%, 11.294 \%, 13.373 \%$ and $12.409 \%$, respectively.

\section{RESULTS AND DISCUSSION}

After performing the validation, the main findings of this paper are summarized and discussed as follows. 


\section{WAVE MEASUREMENT}

For the purpose of monitoring the waves generated at the inlet, a wave probe located $0.5 L_{W L}$ [25] in front of the hull was set to record the wave elevation. Fig. 10 shows the recorded time history of the wave elevation at $\lambda / \mathrm{L}=1.38$. The mean first- order harmonic wave amplitudes of the last ten encounter periods was $0.0284 \mathrm{~m}$. The errors between the simulated wave amplitude and the intended wave amplitude were equal to $5.33 \%$. The slight difference was considered acceptable for the current cell size and time step. The measured wave amplitudes were used to calculate the motion transfer functions in the CFD simulation.

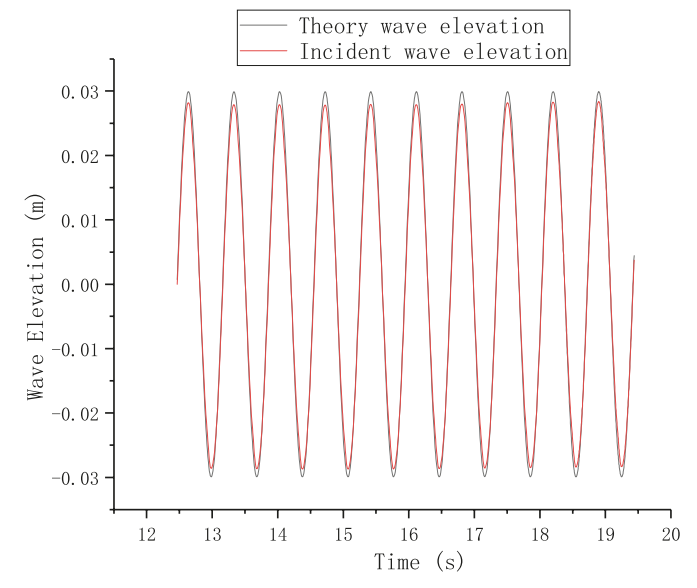

Fig.10 Time history of wave elevation at the wave probe, $\lambda / L=1.38$

\section{CALM WATER RESISTANCE OF TRIMARAN WITH AND WITHOUT T-FOIL}

To investigate the calm water resistance of the trimaran with and without T-foil, numerical simulations and experimental tests were carried out. Tab. 9 presents the experimental and numerical results of the calm water resistance of the bare trimaran. The total resistance from model tests exceeded the total resistance from numerical simulations by about $0.92 \%$, which indicates that the numerical method was able to simulate the calm water resistance of the trimaran with a reasonable small error. Tab. 10 shows the experimental and numerical values of the calm water resistance of the trimaran at different values of T-foil attack angle $\left( \pm 5^{\circ}\right)$. The total resistance from experimental tests also exceeded the total resistance from numerical simulations. The errors between the experimental (EFD) and CFD results turned out to be $2.74 \%$ for $-5^{\circ} \mathrm{T}$-foil attack angle and $2.62 \%$ for $+5^{\circ} \mathrm{T}$-foil attack angle, respectively. Compared to the resistance of the bare trimaran in calm water, the resistance of the trimaran with different T-foil attack angles increased by $8.05 \%$ for T-foil $\left(-5^{\circ}\right)$ : EFD, $7.17 \%$ for T-foil $\left(-5^{\circ}\right)$ : CFD, $9.23 \%$ for T-foil $\left(+5^{\circ}\right)$ : EFD, $6.85 \%$ for T-foil $\left(+5^{\circ}\right)$ : CFD. As a result of the application of the antipitching appendage (i.e.T-foil) the calm water resistance of the trimaran increased, and for different T-foil attack angles different resistance characteristics were revealed. Tab. 10 shows that the trimaran with T-foil attack angle of $-5^{\circ}$ demonstrates preferable calm water resistance characteristics. Therefore, the T-foil attack angle of $-5^{\circ}$ was used as a basic condition in subsequent research on the influence of $\zeta_{\mathrm{a}}{ }^{*} \mathrm{k}$ and size of T-foil on the trimaran motions.

Tab. 9 Calm water resistance of the trimaran without anti-pitching appendages

\begin{tabular}{|l|c|c|}
\hline & EFD (N) & CFD (N) \\
\hline Resistance (N) & 36.84 & 36.50 \\
\hline Error $\left|\frac{C F D-E F D}{E F D}\right|(\%)$ & -- & 0.92 \\
\hline
\end{tabular}

Tab. 10 Calm water resistance of the trimaran with different T-foil attack angles

\begin{tabular}{|l|c|c|c|c|}
\hline & $\begin{array}{c}\text { T-foil } \\
(-5): \\
\text { EFD (N) }\end{array}$ & $\begin{array}{c}\text { T-foil } \\
(-5): \\
\text { CFD (N) }\end{array}$ & $\begin{array}{c}\text { T-foil } \\
(+5): \\
\text { EFD (N) }\end{array}$ & $\begin{array}{c}\text { T-foil } \\
(+5): \\
\text { CFD (N) }\end{array}$ \\
\hline Resistance (N) & 39.804 & 39.116 & 40.242 & 39.186 \\
\hline $\begin{array}{l}\text { Error } \\
|(C F D-E F D) / E F D|(\%)\end{array}$ & --- & 2.74 & --- & 2.62 \\
\hline$\Delta \mathrm{R} \mid \frac{\text { T-Bare }}{\text { Bare }}(\%)$ & 8.05 & 7.17 & 9.23 & 6.85 \\
\hline
\end{tabular}

\section{SHIP MOTION RESPONSE OF BARE TRIMARAN}

Following the model tests and numerical simulations of the trimaran with and without anti-pitching appendages in calm water, the motion response of the trimaran was investigated. The Response Amplitude Operators (RAOs) of heave, pitch motions and vertical acceleration at $19^{\text {th }}$ hull station were compared with the model test results as shown in Figs. $11 \div 13$. In Fig. 11 it can be observed that the CFD method overestimated the heave response values around the resonant period, while under-estimated the heave response values for short and long wave conditions. Fig. 12 indicated that the CFD method under-estimated the pitch response values around the resonant period. Fig. 13 showed that the CFD method was in a good agreement with the experimental results around the resonant period, while under-estimated the vertical acceleration at 19th hull station for short and long wave conditions. In general, the CFD method used in this paper was capable of calculating the longitudinal motions of the bare trimaran with a relative high speed. 


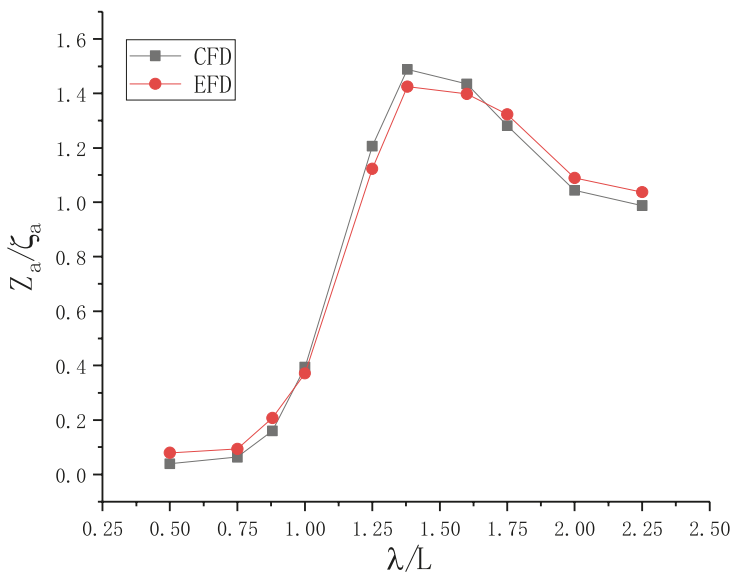

Fig.11 Heave RAO

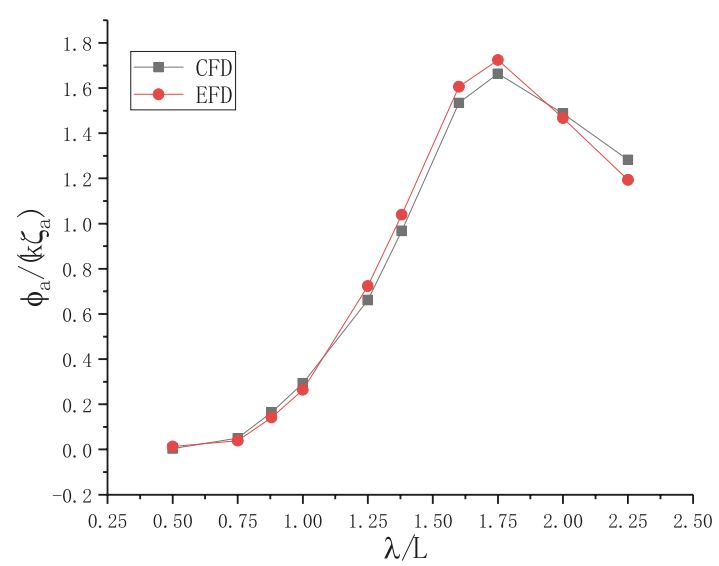

Fig.12 Pitch RAO

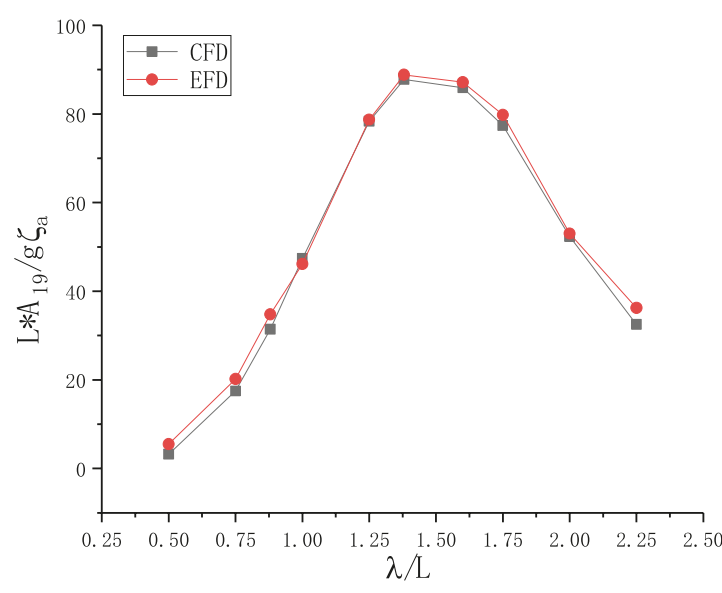

Fig.13 RAO of acceleration at $19^{\text {th }}$ hull station ( A19)

\section{SHIP MOTIONS OF TRIMARAN FITTED WITH T-FOIL}

The longitudinal motions of the trimaran at high speed are severe. For the purpose of improving the seakeeping performance of the trimaran, T-foil was used as an antipitching appendage to reduce the motion response of the trimaran in waves. The selected wave conditions are considered identical to those applied to the simulations of the bare trimaran. In considering the calm water resistance characteristics of the trimaran with T-foil, only the T-foil attack angle of $-5^{\circ}$ was taken into account in this section.

Response values of heave and pitch motions and vertical acceleration at $19^{\text {th }}$ hull station calculated by the CFD method were compared with the results of the experiment as shown in Figs. $14 \div 16$. In Fig. 14 it can be observed that the CFD method under-estimated the heave response values, especially for the short waves $(\lambda / L<0.88)$, which can be explained by that for short waves higher requirements as to grid setting are necessary. The amplitude of the heave response is reduced by $19.6 \%$ in case of the CFD method and $13.6 \%$ for experimental results. Fig. 15 indicates that the CFD method was in a good accordance with the experimental results. The amplitude of the pitch response is reduced by $39.1 \%$ for CFD method and $42.4 \%$ for experimental results. Fig. 16 shows that the CFD method a little under-estimated the vertical acceleration at $19^{\text {th }}$ hull station. The amplitude of the acceleration is reduced by $41.3 \%$ for CFD method and $40.1 \%$ for experimental results. Figs. $14 \div 16$ obviously show that the T-foil can significantly reduce the longitudinal motions response values of the trimaran with a high speed.

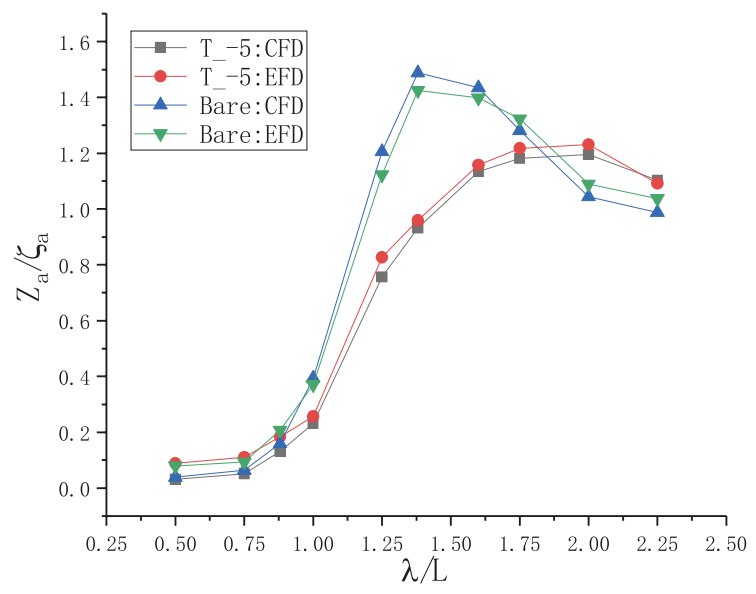

Fig. 14 Heave RAO

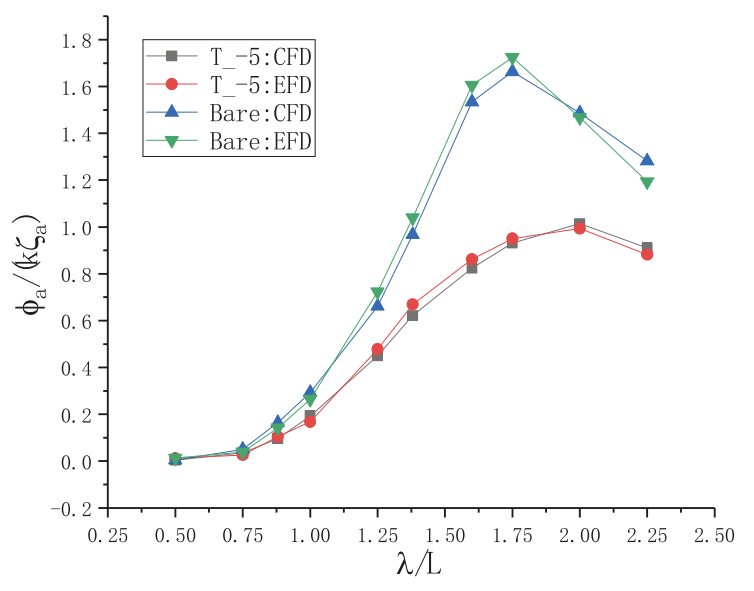

Fig.15 Pitch RAO 


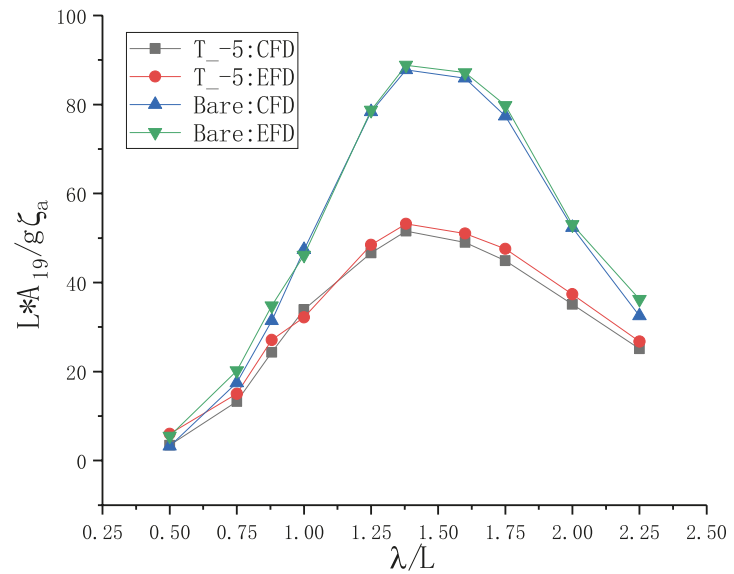

Fig.16 RAO of acceleration at $19^{\text {th }}$ hull station ( A19)

\section{SHIP MOTIONS OF TRIMARAN IN THE CONDITION OF $\zeta_{a}^{*} K=0.1$}

Longitudinal motion characteristics of the trimaran with and without T-foil were investigated in the condition of $\zeta_{\mathrm{a}}{ }^{*} \mathrm{k}$ within the range of 0.046 (longest wave) and 0.063 (shortest wave). In the considered situations, a high amplitude may occur making a different influence on the ship motion in waves. The longitudinal motions of the trimaran with and without $\mathrm{T}$-foil in the condition of $\zeta_{\mathrm{a}}{ }^{*} \mathrm{k}=0.1$ were investigated. The wave conditions for the CFD calculations are shown in Tab. 11. As can be seen in Tab. 11, the wave amplitude $\zeta_{a}$ times wave number is equal to about 0.1 .

Tab. 11 Calm water resistance of the trimaran without anti-pitching appendages

\begin{tabular}{|c|c|c|}
\hline $\begin{array}{c}\text { Wave length } \\
\left(\lambda / L_{p p}\right)\end{array}$ & $\begin{array}{c}\text { Wave amplitude } \\
\zeta_{\mathrm{a}}(\mathrm{m})\end{array}$ & $\zeta_{\mathrm{a}}{ }^{*} \mathrm{k}$ \\
\hline 0.50 & 0.024 & 0.101 \\
\hline 0.75 & 0.036 & 0.101 \\
\hline 0.88 & 0.042 & 0.100 \\
\hline 1.0 & 0.048 & 0.101 \\
\hline 1.25 & 0.060 & 0.101 \\
\hline 1.38 & 0.066 & 0.100 \\
\hline 1.60 & 0.077 & 0.101 \\
\hline 1.75 & 0.084 & 0.101 \\
\hline 2.0 & 0.096 & 0.101 \\
\hline 2.25 & 0.108 & 0.101 \\
\hline
\end{tabular}

Response values of heave and pitch motions and vertical acceleration at $19^{\text {th }}$ hull station calculated by the CFD method are shown in Figs. $17 \div 19$. In the figures it can be observed that in the wave condition $\zeta_{a}{ }^{*} \mathrm{k}=0.1$, the $\mathrm{T}$-foil played some role in reducing the amplitudes of heave, pitch and acceleration. The amplitudes of the heave, pitch and acceleration were reduced by $22.72 \%, 20.93 \%$ and $22.16 \%$, respectively. With the wave amplitude increasing, the T-foil had different influence on values of heave and pitch motion and acceleration. The effect of reducing heave motion appeared a little greater, but in contrast, the effect of reducing pitch motion and acceleration became lower, the reduction was from $39.1 \%$ to $20.93 \%$ for pitch motion and $42.4 \%$ to $22.16 \%$ for acceleration motion.

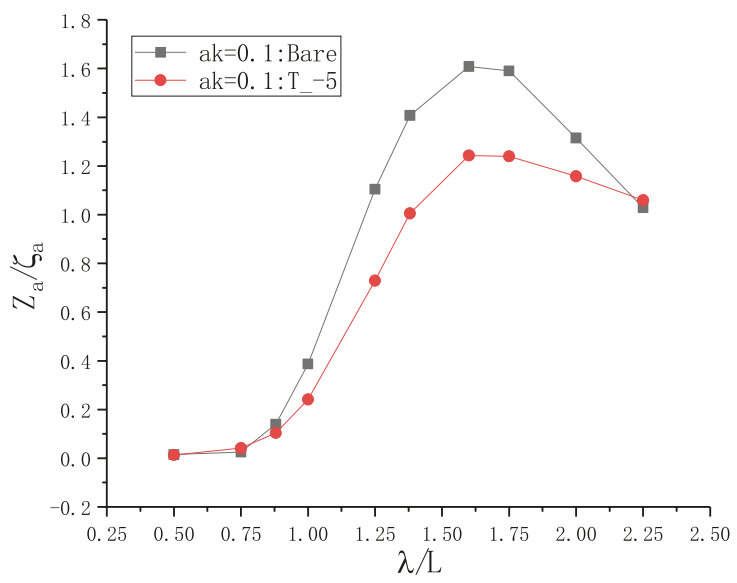

Fig. 17 Heave RAO

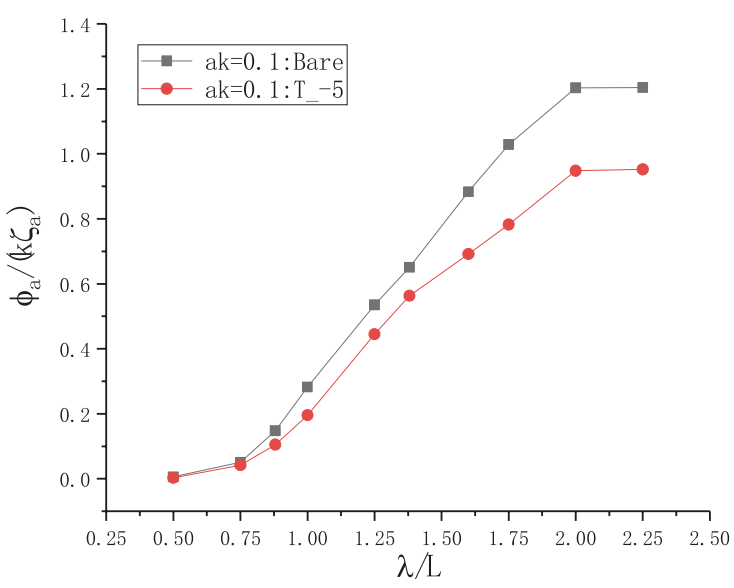

Fig.18 Pitch RAO

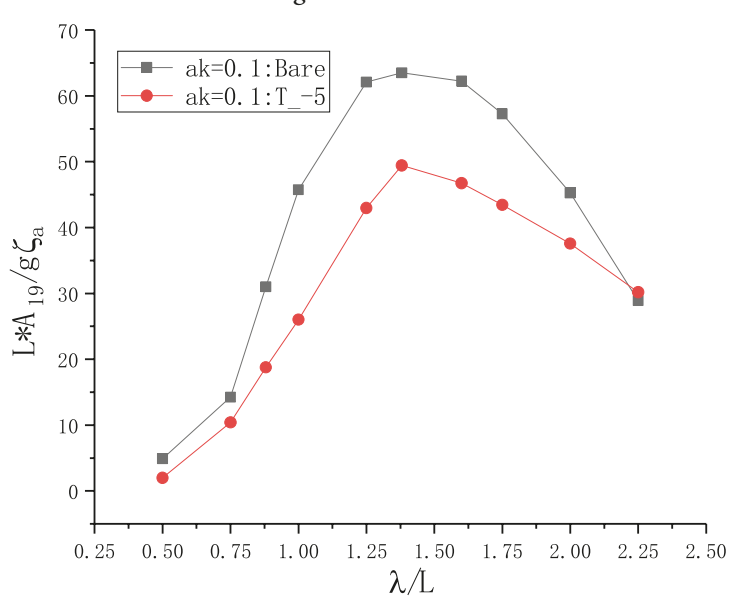

Fig.19 RAO of acceleration at $19^{\text {th }}$ hull station ( A19) 


\section{INFLUENCE OF T-FOIL SIZE ON TRIMARAN MOTIONS}

To investigate the influence of size of T-foil on trimaran motions, three sizes of T-foil were considered. During the CFD simulations, the applied T-foil was of the dimensions decreased and enlarged by $20 \%$ in each direction for the horizontal wings, with other parameters unchanged. The dimensions of the so differentiated T-foils are shown in Tab. 12. The T-foil origin size was marked T2.

Tab.12 Dimensions of the different -size T-foils

\begin{tabular}{|l|l|l|l|}
\hline Principal particulars & \multicolumn{1}{|c|}{ T1 } & \multicolumn{1}{|c|}{ T2 } & \multicolumn{1}{|c|}{ T3 } \\
\hline Airfoil shape & \multicolumn{3}{|c|}{ NACA0012 } \\
\hline Span $(\mathrm{m})$ & 0.1152 & 0.144 & 0.1728 \\
\hline Chord $(\mathrm{m})$ & 0.0768 & 0.096 & 0.1152 \\
\hline Aspect ratio & 1.5 & 1.5 & 1.5 \\
\hline Rotating angle of the flap () & -5 & -5 & -5 \\
\hline Width of the vertical foil (m) & 0.01 & 0.01 & 0.01 \\
\hline Length of the vertical foil (m) & 0.060 & 0.060 & 0.060 \\
\hline Height of the vertical foil (m) & 0.024 & 0.024 & 0.024 \\
\hline $\begin{array}{l}\text { Longitudinal position of foil } \\
\text { installation place (distance between } \\
\text { centre line of vertical foil and 10 } \\
\text { station of the trimaran) (m) }\end{array}$ & 1.320 & 1.320 & 1.320 \\
\hline
\end{tabular}

The response values of heave and pitch motions and vertical acceleration at $19^{\text {th }}$ hull station calculated by the CFD method are shown in Figs. $20 \div 22$. In the figures it can be observed that each of the three T-foils of different size produced different effect on the longitudinal motion response values of the trimaran. The trends of the RAOs were the same for the considered different-size T-foils. With the increase of the T-foil dimensions, their effect on pitching stabilization became greater. The amplitudes of the heave, pitch and acceleration were reduced by $17.68 \%, 15.17 \%$ and $13.15 \%$ for $\mathrm{T} 1$ foil and $29.72 \%, 25.73 \%$ and $31.44 \%$ for $\mathrm{T} 3$ foil, respectively.

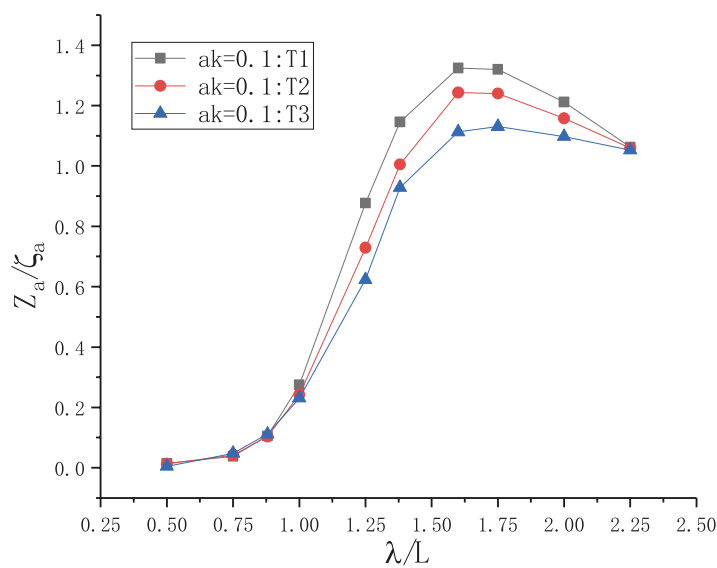

Fig.20 Heave RAO

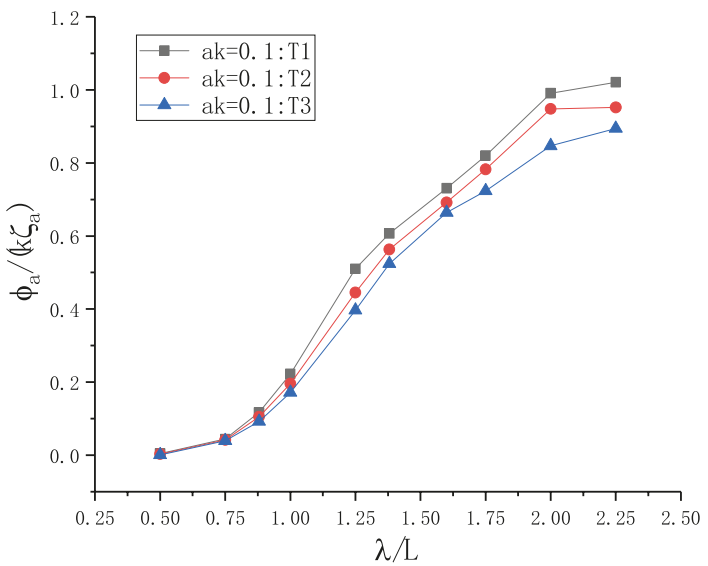

Fig.21 Pitch RAO

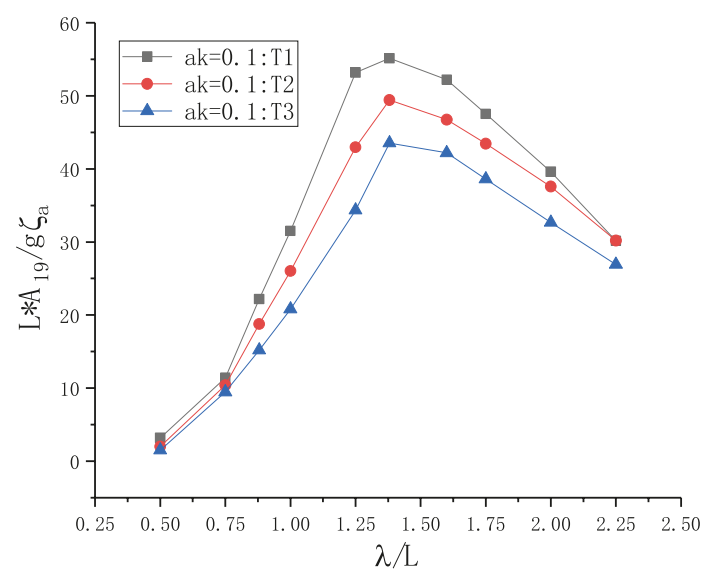

Fig. 22 RAO of acceleration at $19^{\text {th }}$ hull station ( A19)

In addition, the influence of the change of T-foil size on the calm water resistance of the trimaran, were studied. Tab. 13 shows the results of the numerical calculations of the calm water resistance of the trimaran with T-foils of different size. Compared to the calm water resistance of the bare trimaran, the resistance of the trimaran with T-foils of different size increased by $5.28 \%$ for $\mathrm{T} 1(-5 \mathrm{o}), 7.17 \%$ for $\mathrm{T} 2\left(-5^{\circ}\right), 11.53 \%$ for $\mathrm{T} 3\left(-5^{\circ}\right)$. With increasing $\mathrm{T}$-foil dimensions, the calm water resistance of the trimaran increases.

Tab.13 Calm water resistance of the trimaran with T-foils of different size

\begin{tabular}{|l|c|c|c|}
\hline & $\begin{array}{c}\text { T1(-5): } \\
\text { CFD(N) }\end{array}$ & $\begin{array}{c}\text { T2 (-5): } \\
\text { CFD (N) }\end{array}$ & $\begin{array}{c}\text { T3 (-5): } \\
\text { CFD (N) }\end{array}$ \\
\hline Resistance $(\mathrm{N})$ & 38.426 & 39.116 & 40.707 \\
\hline$\Delta \mathrm{R} \mid(\mathrm{T}-$ Bare $) /$ Bare $\mid(\%)$ & 5.28 & 7.17 & 11.53 \\
\hline
\end{tabular}

\section{CONCLUDING REMARKS AND DISCUSSION}

In the present work, to investigate the seakeeping and resistance characteristics of the trimaran at a relative high speed $\left(F_{n}=0.628\right)$, the unsteady RANS method was used 
to simulate the calm water resistance of the trimaran, the longitudinal ship motions (heave and pitch ) and vertical acceleration at $19^{\text {th }}$ hull station for a broad range of wave conditions. The wave conditions covered a series of wavelength $\lambda$ varying between $1.5 \mathrm{~m}$ and $6.75 \mathrm{~m}$, thus the $\lambda / \mathrm{L}$ ratio varied between 0.50 and 2.25 .

The longitudinal motion responses of the trimaran at a relative high speed were rather intense. In order to reduce the longitudinal motions of the trimaran a T-foil was used as an anti-pitching appendage which was located at the $19^{\text {th }}$ hull station near the bow of the middle hull of the trimaran. The T-foil can significantly reduce the amplitude of the longitudinal motions of the trimaran, but the increase of calm water resistance was a detrimental effect.

All experimental measurements obtained from the model tests were used for comparison with numerical results. Therefore, to avert scaling errors, all numerical investigations were conducted in corresponding model scale.

The STAR-CCM+ unsteady RANS solver was used for the simulation of the trimaran behaviour. The method was extended by an explicit six-degrees-of-freedom solver to compute nonlinear ship motions. CFD simulations have been validated by comparison with results of the experimental tests. The verification study at the resonant frequency demonstrated that the numerical results were more sensitive to the time step than to the mesh size. The validation was positive for all the considered variables.

Comparisons between the experimental results and numerical calculations showed that the unsteady RANS method predicts ship longitudinal motions with a high accuracy.

Compared with the results for the bare trimaran, the use of anti-pitching appendage in the form of T-foil greatly reduced the longitudinal motions. In the wave condition of $\zeta_{\mathrm{a}}{ }^{\star} \mathrm{k}=0.1$, the amplitudes of the heave, pitch and acceleration were reduced with the help of T-foil by $22.72 \%, 20.93 \%$ and $22.16 \%$, respectively. In the wave condition of $\zeta_{a}{ }^{*} \mathrm{k}$ of a value between 0.046 and 0.063 , the T-foil produced a little greater effect on heave motion, but its effect on pitch and acceleration was reduced by about $20 \%$. With the increase of T-foil size, the effect of reducing longitudinal motions becomes greater, however, the calm water resistance of the trimaran increases by $5.28 \%$ to $11.53 \%$ compared with the bare trimaran.

The nonlinear effects on the longitudinal motions of the trimaran in wave of a relatively high amplitude will be further investigated experimentally in the future. The use of T-foil can significantly reduce longitudinal motions but has a negative effect on resistance, therefore the combined use of T-foil and stern flap will be further studied with the aim to realize the comprehensive optimization of resistance and seakeeping performance of the trimaran.

\section{BIBLIOGRAPHY}

1. Davis, M.R., Holloway, D.S.: A comparison of the motions of trimarans, catamarans and monohulls. Australian Journal of Mechanical Engineering, 4(2), (2007). pp. 183-195.

2. Mynard, T. : Numerical and experimental study of wave resistance for trimaran hull forms. Vol.1, (2008), pp.117-132.

3. Brizzolara, S., Capasso, M., Ferrando, M., et al. : Trimaran hull design for fast ferry applications. Int. Conference on Ships Design and Shipping, Nav. 2003.

4. Bertorello, C., Bruzzone, D., Cassella, P., et al. : Trimaran model test results and comparison with different high speed craft. Practical Design of Ships \& Other Floating Structures, 1, (2001), pp. 143-149.

5. Hebblewhite, K., Sahoo, P.K. and Doctors, L.J.: A case study: theoretical and experimental analysis of motion characteristics of a trimaran hull form, Ships and Offshore Structures, 2:2, (2007) , pp.149 - 156.

6. Faltinsen, O.M. : Numerical prediction of ship motions at high forward speed. Phil. Trans. R. Soc. , London Ser. A, 334, (1991), pp. 241-252.

7. Salvesen, N., Tuck, E.O., Faltinsen, O.M. : Ship Motion and Sea Loads. SNAME, 1970.

8. Wei, Y.F., Duan, W.Y., Ma, S. : Trimaran motions and hydrodynamic interaction of side hulls, 9th International Conference on Fast Sea Transportation, FAST 2007, pp. 413-421.

9. Wang, S. M., Ma, S., \& Duan, W. Y.: Seakeeping optimization of trimaran outrigger layout based on NSGA-II. Applied Ocean Research, 78, (2018), pp. 110-122.

10. Sato, Y., Uzawa, K., Miyata, H. : Validation of motion prediction method for trimaran vessels. International Conference on Numerical Ship Hydrodynamics 2007, (Vol.5).

11. Wu, C.S, Zhou, D.C, Gao, L., et al. :). CFD computation of ship motions and added resistance for a high speed trimaran in regular head waves, International Journal of Naval Architecture and Ocean Engineering, 3(1), (2011), pp. 105-110. doi: https://doi.org/10.2478/ijnaoe-2013-0051.

12. Poundra, G.A.P., Utama, I.K.A.P., Hardianto, D., et al. : Optimizing trimaran yacht hull configuration based on resistance and seakeeping criteria. Procedia Engineering, 194, (2017), pp. 112-119.

13. Fang, C.C., Chan, H.S. : An investigation on the vertical motion sickness characteristics of a high-speed catamaran ferry. Ocean Engineering, 34(14), (2007), pp. 1909-1917.

14. Esteban, S., Giron-Sierra, J.M., Andres-Toro, B.D., et al. : Fast ships models for seakeeping improvement studies using 
flaps and t-foil. Mathematical \& Computer Modelling,41(1), (2005), pp. 1-24.

15. Haywood A.J., Duncan A.J., Klaka K.P. et al. : The development of a ride control system for fast ferries. Control Eng. Pract. 3(5), (1995), pp. 695-702.

16. Giron-Sierra J.M., Esteban S, Andres D., et al. : Experimental study of controlled flaps and T-foil for comfort improvement of a fast ferry. In: IFAC Proceedings control applications in marine systems, vol. 34, (2001), pp. 261-266.

17. Zong, Z., Sun, Y., Jiang, Y. : Experimental study of controlled T-foil for vertical acceleration reduction of a trimaran. Journal of Marine Science \& Technology, (2018), pp. 1-12.

18. CD-Adapco. User guide of STAR-CCM+, Version 11.0.2, 2016.

19. Patankar, S.V., Spalding, D.B. : A calculation procedure for heat, mass and momentum transfer in three-dimensional parabolic flows. Int. J. Heat. Mass Transf. 15 (2), (2005), pp. 1787-1806.

20. Tezdogan, T., Demirel, Y.K., Kellett, O., et al. : Full-scale unsteady RANS CFD simulations of ship behavior and performance in head seas due to slow steaming. Ocean Eng. 97, (2015), pp. 186-206.

21. International Towing Tank Conference (ITTC) : Practical guidelines for ship CFD applications. In: Proceedings of the 26th ITTC, Rio de Janeiro, Brazil, 2011b.

22. Choi, J., Yoon, S.B. : Numerical simulations using momentum source wave-maker applied to RANS equation model. Coast. Eng. 56 (10), (2009), pp. 1043-1060.

23. Sun, H.B., Jing, F.M., Jiang, Y., et al. : Motion prediction of catamaran with a semi-submersible bow in wave. Polish Maritime Research 1(89), Vol. 23, 2016 , pp. 37-44

24. Stern, F., Wilson, R., Shao, J. : Quantitative V\&V of CFD simulations and certification of CFD codes. International Journal for Numerical Methods in Fluids, 50(11), (2006), pp. 1335-1355.

25. Sun, X.S., Yao, C.B., Xiong, Y., et al.: Numerical and experimental study on seakeeping performance of a swath vehicle in head waves. Applied Ocean Research, 68, (2017), pp. 262-275.

26. International Towing Tank Conference (ITTC), Ocean Engineering Committee : Final report and recommendation to the 27th ITTC. In: Proceedings of the 27th ITTC, Copenhagen, 2014.
27. Bøckmann, A., Pakozdi, C., Kristiansen, T., et al. : An Experimental and Computational Development of a Benchmark Solution for the Validation of Numerical Wave Tanks. ASME 2014, International Conference on Ocean, Offshore and Arctic Engineering (2014), Vol.2, pp. V002T08A092-V002T08A092.

28. Kim, M., Hizir, O., Turan, O., et al.: Estimation of added resistance and ship speed loss in a seaway. Ocean Engineering 141, (2017), pp. 465-476.

29. Kim, M., Turan, O., Day, S., et al. : Numerical studies on added resistance and ship motions of KVLCC2 in waves. Ocean Engineering 140, (2018), pp. 466-476.

30. Hizir, O., Kim, M., Turan, O., et al. : Numerical studies on non-linearity of added resistance and ship motions of KVLCC2 in short and long waves. International Journal of Naval Architecture and Ocean Engineering ,(2018). https:// doi.org/10.1016/j.ijnaoe.2018.02.015.

\section{CONTACT WITH THE AUTHORS}

\author{
Ang Li \\ e-mail:liang0301@hrbeu.edu.cn \\ College of Shipbuilding Engineering \\ Harbin Engineering University \\ Harbin \\ CHINA \\ Yunbo Li \\ e-mail:multihull@163.com \\ College of Ocean Science and Engineering \\ Shanghai Maritime University \\ Shanghai \\ CHINA
}

